\title{
Ô NHIỄM HÓA CHẤT
}

Trần Phương Nga, Phan Thị Kim Ngân, Mai Thanh Ngọc, Phan Thị Bảo Ngọc, Nguyễn Thị Nguyên, Nguyễn Ý Nhi, Lê Ngân Phương, Nguyễn Thu Phương, Nguyễn Minh Quang, Ngô Việt Quân

Môi trường từ lâu luôn là vấn đề được quan tâm nhất ở quá khứ hay hiện tại và kể cả trong tương lai. Dưới sự tác động của công cuộc đổi mới, con người có sự phát triển vượt bậc về mọi mặt đặc biệt được xây dựng theo hướng công nghiệp hóa, hiện đại hóa.

Xã hội loài người đang tiến dần hơn đến sự phát triển bền vững, quá trình chuyển đổi và kéo theo không ít những vấn đề phát sinh gây hại đặc biệt đó là tình trạng ô nhiễm môi trường và đặc biệt là ô nhiễm hóa chất do chất thải của nền công nghiệp công nghệ kỹ thuật mà con người cho rằng máy móc sẽ thay thế hoàn toàn sức người. Nếu không được quan sát và đưa ra những giải pháp cụ thể thì nó sẽ gây nên hậu quả nghiêm trọng đến chất lượng sống của con người và từ đó, con người không thể tiến lên phía trước mà đang bị bào mòn cuộc sống như cách mà những hóa chất độc hại kia từng chút gặm nhấm môi trường xung quanh ta. Đây cũng là vấn đề nan giải đối với những nước đang phát triển muốn đột phá thành những quốc gia phát triển.

Vấn đề ô nhiễm hóa chất hiện nay đang ở mức đáng báo động, có người nói rằng tỉ lệ phát triển của con người nghịch biến với sự phát triển của đất mẹ. Lý do vì sao, trên thực tế khi con người ta càng phát triển, tức càng có nhiều phát minh được sáng tạo ra, để nó tồn tại và vận hành cần một nguồn năng lượng cung cấp. Việc mọc càng nhiều những phát minh như vậy tuy đem đến nhiều lợi ích nhưng song song với đó cũng là mặt hại đối với môi trường nếu ta không biết đem các chất xử lý theo quy trình. Hơn nữa việc sử dụng hóa chất một cách bừa bãi, không có kiến thức cũng là một trong những thực trạng ngày nay đáng lo ngại, mỗi hóa chất nếu được sử dụng theo liều lượng nhất định sẽ đem đến lợi ích còn nếu sử dụng đến 
mức quá cao hoặc mức có thể tiết ra độc ( bản thân hóa chất đã tồn tại chất gây hại) ảnh hướng xấu đến xung quanh.

Nguyên nhân gây ra tình trạng ô nhiễm hóa chất bắt nguồn từ rất nhiều lý do. Trước hết, các đơn vị ban ngành, người dân còn nhận thức chưa sâu về việc sử dụng hóa chất bừa bãi làm tác dụng phụ như chất độc từ hóa chất dồn nén, tích trữ lâu ngày gây nên hậu quả nghiêm trọng. Không chỉ vậy, vị trí địa lý ngày càng phức tạp, xuất hiện các vị trí có diện tích nhỏ lẻ, ngoằn ngoèo gây nên khó khăn trong công tác kiểm tra, trích xuất nguồn tên các hóa chất, dẫn đến khó khăn trong công tác xử lí tàn dư chất ô nhiễm. Hơn thế nữa, chính quyền quản lý lỏng lẻo việc sử dụng và lưu trữ hóa chất, ngân sách không đủ phục vụ cho các máy móc, công nghệ xử lí chất ô nhiễm, thiếu tình nguyện viên đứng ra giúp đỡ chính quyền địa phương. Bên cạnh đó, với các nước đang phát triển, dây chuyền và các thiết bị xử lý hóa chất còn lạc hậu, chỉ đạt mức độ trung bình.

Ô nhiễm hóa chất đã và đang có những tác động tiêu cực, thậm chí để lại hậu quả nghiêm trọng đến cả môi trường và sức khỏe con người. Đối với môi trường, phân bón hoặc nước thải có thể đưa các hóa chất có chứa nitrat hoặc photphat vào các vùng nước. Thức ăn của tảo chính là nitrat và photphat. Quá tải các hóa chất này sẽ khiến tảo nở hoa. Khi lượng tảo dư thừa chết và thối rữa, oxy hòa tan được sử dụng hết và chất lượng tổng thể của nước bị suy giảm. Do đó, sinh vật sống dưới nước chết vì thiếu oxy. Thậm chí, khi tiếp xúc lâu dài với các chất ô nhiễm hóa học khiến các loài bản địa trong hệ sinh thái chết đi, khu vực này sẽ mất đi tính đa dạng và trở nên dễ bị tổn thương hơn trước các loài xâm lấn và không mong muốn. Trong một số trường hợp, ô nhiễm hóa chất có thể giết chết quần thể các loài có ích hỗ trợ hệ sinh thái, như ong. Còn đối với sức khỏe con người, do thường xuyên tiếp xúc với hóa chất như ô nhiễm không khí xung quanh, ô nhiễm không khí gia đình, khói thuốc lá thụ động và chì, "hơn một phần ba (35\%) bệnh tim thiếu máu cuc bộ, nguyên nhân hàng đà̀u gây tư vong và tàn tật trên toàn thế giới, và khoảng $42 \%$ bệnh đột quy, nguyên nhân lớn thư hai đối với tỷ lệ tư vong toàn cầu." "Các truờng hợp ngộ độc không chủ ý được uớc tính gây ra 193.000 ca tư vong hàng năm" với phần lớn là do phơi nhiễm hóa chất độc hại. Tiếp xúc với một số hóa chất nhất định, như chì, đã được chứng minh có 
liên quan đến giảm phát triển hệ thần kinh ở trẻ em và làm tăng nguy cơ bị chứng rối loạn thiếu tập trung và khuyết tật trí tuệ, chẳng hạn như "bệnh Parkinson có liên quan đến việc tiếp xúc với thuốc trù̀ sâu".

Để minh chứng rõ hơn những ảnh hưởng nghiêm trọng của ô nhiễm hóa chất, sau đây là bảng phân tích thống kê ô nhiễm hóa chất ở các thành phố trên thế giới cùng với những thiệt hại mà ô nhiễm hóa chất đã gây ra:

\begin{tabular}{|c|c|c|c|c|}
\hline $\begin{array}{c}\text { Thành } \\
\text { phố }\end{array}$ & $\begin{array}{l}\text { Nguồn gây } \\
\text { ô nhiễm }\end{array}$ & $\begin{array}{c}\text { Chất gây ô } \\
\text { nhiễm }\end{array}$ & $\begin{array}{c}\text { Số người } \\
\text { có nguy co' } \\
\text { bị ảnh } \\
\text { hưởng }\end{array}$ & Thiệt hại \\
\hline $\begin{array}{l}\text { Thiên } \\
\text { Tân, } \\
\text { Trung } \\
\text { Quốc }\end{array}$ & $\begin{array}{l}\text { Mỏ và công } \\
\text { nghiệp chế } \\
\text { biến }\end{array}$ & $\begin{array}{l}\text { Chì và các } \\
\text { kim loại } \\
\text { nặng }\end{array}$ & $\begin{array}{l}140 \text { nghìn } \\
\text { người }\end{array}$ & $\begin{array}{l}\text { Làm giảm chỉ số thông } \\
\text { minh } \\
\text { Lượng chì tăng cao gấp } \\
24 \text { lần }\end{array}$ \\
\hline $\begin{array}{l}\text { Sukinda, } \\
\text { Ân Độ }\end{array}$ & $\begin{array}{l}\text { Mỏ crom và } \\
\text { công nghiệp } \\
\text { chế biến }\end{array}$ & $\begin{array}{l}\text { Crom hóa trị } \\
\text { sáu và các } \\
\text { kim loại } \\
\text { khác }\end{array}$ & $\begin{array}{l}\text { 2,6 triệu } \\
\text { người }\end{array}$ & $\begin{array}{l}\text { 60\% nước bị nhiễm crom } \\
84,7 \% \text { số người chết do } \\
\text { bệnh crom gây ra }\end{array}$ \\
\hline $\begin{array}{l}\text { La Oraya, } \\
\text { Peru }\end{array}$ & $\begin{array}{l}\text { Các mỏ khai } \\
\text { thác kim } \\
\text { loại nặng và } \\
\text { cơ sở chế } \\
\text { biến }\end{array}$ & $\begin{array}{l}\text { Chì, đồng, } \\
\text { kẽm và } \\
\text { sulfur } \\
\text { dioxide }\end{array}$ & $\begin{array}{l}35 \text { nghìn } \\
\text { người }\end{array}$ & $\begin{array}{l}99 \% \text { số trẻ em có lượng } \\
\text { chì nhiễm vào máu } \\
\text { Hàm lượng chì trung bình } \\
\text { cao gấp } 3 \text { lần so với giới } \\
\text { hạn cho phép }\end{array}$ \\
\hline $\begin{array}{l}\text { Dzerzhins } \\
\mathrm{k}, \mathrm{Nga}\end{array}$ & $\begin{array}{l}\text { Việc sản } \\
\text { xuất vũ khí } \\
\text { hóa học từ }\end{array}$ & $\begin{array}{l}\text { Các hóa chất } \\
\text { và các sản } \\
\text { phẩm phụ }\end{array}$ & $\begin{array}{l}300 \text { nghìn } \\
\text { người }\end{array}$ & $\begin{array}{l}\text { Nhiễm dioxin và phenol } \\
\text { cao gấp } 17 \text { triệu lần mức } \\
\text { an toàn }\end{array}$ \\
\hline
\end{tabular}




\begin{tabular}{|l|l|l|l|l|}
\hline & $\begin{array}{l}\text { thời Chiến } \\
\text { tranh lạnh }\end{array}$ & $\begin{array}{l}\text { độc hại, } \\
\text { trong đó có } \\
\text { sarin và khí } \\
\text { VX }\end{array}$ & $\begin{array}{l}\text { Năm 2003, tỷ lệ chết tại } \\
\text { thành phố cao hơn } 260 \% \\
\text { so với tỷ lệ sinh }\end{array}$ \\
\hline $\begin{array}{l}\text { Chernobyl } \\
\text {, Ukraine } \\
\text { hạt nhân }\end{array}$ & Phóng xạ xạ & $\begin{array}{l}5,5 \text { triệu } \\
\text { người }\end{array}$ & $\begin{array}{l}\text { Khu vực cấm có bán kính } \\
\text { 30 km quanh nhà máy } \\
\text { Mắc bệnh ung thư tuyến } \\
\text { giáp khi sống ở khu vực }\end{array}$ \\
\hline $\begin{array}{l}\text { Sumgayit, } \\
\text { Azerbaija }\end{array}$ & $\begin{array}{l}\text { Các tổ hợp } \\
\text { công nghiệp } \\
\text { và hóa dầu }\end{array}$ & $\begin{array}{l}\text { Các hóa chất } \\
\text { hữu cơ, dầu } \\
\text { mỏ và các } \\
\text { kim loại } \\
\text { nặng }\end{array}$ & người & $\begin{array}{l}\text { Những nhà máy hoạt động } \\
\text { thải 120 nghìn tấn chất } \\
\text { độc hại đã đóng cửa } \\
\text { Chất ô nhiễm vẫn còn tồn } \\
\text { tại }\end{array}$ \\
\hline $\begin{array}{l}\text { Kabwe, } \\
\text { Zambia }\end{array}$ & $\begin{array}{l}\text { Việc khai } \\
\text { thác và chế } \\
\text { biến chì }\end{array}$ & $\begin{array}{l}\text { Chì và } \\
\text { cadmium }\end{array}$ & $\begin{array}{l}255 \text { nghìn } \\
\text { người }\end{array}$ & $\begin{array}{l}\text { Hàm lượng chì có trong } \\
\text { máu trẻ em ở đây cao gấp } \\
5-10 \text { lần mức chấp nhận } \\
\text { được }\end{array}$ \\
\hline
\end{tabular}

Có thể nói, khả năng khôi phục hoàn toàn sau thảm họa ô nhiễm hóa chất là không thể bởi những chất hóa học thường thấm sâu và đã thay đổi cấu trúc của các sự vật khiến nó nhiễm bệnh và khó loại trừ hết. Vì vậy, trước những tác hại khôn lường mà ô nhiễm hóa chất gây ra, con người cần đưa ra những biện pháp cấp bách để giảm thiểu cũng như tiến tới xóa bỏ tình trạng ô nhiễm hóa chất.

Chính phủ các nước cũng như các tổ chức trên thế giới đã và đang rất nỗ lực đưa ra các giải pháp, chính sách để hạn chế, giảm thiểu tình trạng ô nhiễm hóa chất. Rất nhiều các công ước đã được ký kết, nhiều dự án được triển khai, tiêu biểu phải kể đến một số công ước và dự án sau: 
- Công uớc Stockholm về các chất ô nhiễm hũu co khó phân hủy (22/05/2001) nhằm mục đích loại bỏ việc sản xuất, sử dụng và phát thải các chất POP đồng thời ngăn chặn sự ra đời của các hóa chất mới có đặc tính giống POP và đảm bảo tiêu hủy hợp lý môi trường đối với các kho dự trữ chất thải POP.

- Công uớc Minamata về thủy ngân (9/1/2013) là hiệp ước toàn cầu nhằm bảo vệ sức khỏe con người và môi trường do những ảnh hưởng có hại của thủy ngân.

- Công ước Rotterdam (24/02/2004) quy định chi tiết các thủ tục xuất nhập khẩu đối với một số hóa chất công nghiệp và thuốc trừ sâu độc hại.

- Công ước Basel (05/05/1992) nhằm mục tiêu giảm thiểu phát sinh chất thải nguy hại; khuyến khích hủy bỏ các chất thải nguy hại gần nguồn phát sinh, giảm việc di chuyển các chất này qua các biên giới và bảo đảm cho chất thải được quản lý một cách tốt nhất để bảo vệ môi trường.

- Quỹ môi trường toàn cầu $(G E F)$ đóng vai trò xúc tác trong việc tận dụng các nguồn ngân sách từ chính phủ các nước và khuyến khích khu vực tư nhân đóng góp nhiều hơn để đạt được việc loại bỏ và giảm thiểu các hóa chất và chất thải độc hại.

- Dự án An toàn Hóa chất Trung Quốc (2012-2014) được thực hiện bởi tổ chức IPEN do EU tài trợ cùng với các đối tác phi chính phủ của Séc và Trung Quốc, Arnika và Green Beagle, nhằm nâng cao nhận thức liên quan đến khí thải, hoá chất, tăng cường năng lực của các tổ chức xã hội dân sự và cộng đồng người bị ảnh hưởng bởi ô nhiễm hoá chất ở Trung Quốc.

Còn ở Việt Nam hiện nay cũng đã áp dụng một số biện pháp giúp giảm thiểu tình trạng ô nhiễm hoá chất ví dụ như:

- Các công ty, doanh nghiệp hiện nay nhìn chung đặc biệt chú ý đến việc lựa chọn công nghệ ít gây ô nhiễm, đáp ứng các yêu cầu về môi trường của Việt Nam.

- Xây dựng hệ thống thu gom và xử lý nước thải, khí thải, chất thải rắn. 
- Khu vực nông nghiệp và dân cư nông thôn: Khuyến cáo người dân sử dụng hợp lý hóa chất trong sản xuất nông nghiệp, từng bước tiến dần đến phát triển nông nghiệp sạch

- Khu vực đất trống nhiều cây xanh cần có biện pháp chăm sóc hợp lý, hạn chế sử dụng hoá chất.

- Xây dựng hệ thống thoát nước và xử lý nước thải sinh hoạt như nội dung đề xuất quy hoạch. Nước thải sinh hoạt sau khi xử lý phải đạt QCVN 14:2008/BTNMT trước khi xả vào nguồn tiếp nhận

- Giảm phát thải khí nhà kính thông qua việc phát triển mạng lưới giao thông công cộng với các phương tiện sử dụng năng lượng sạch như tàu điện, ... giảm phương tiện giao thông cá nhân. VD: Công ty Xu-pe phốt-phát và Hóa chất Lâm Thao đã chuyển đổi công nghệ sản xuất a-xít sun-phurich $(\mathrm{H}$ 2SO4 ) từ đốt py-rit sang lưu huỳnh, chuyển từ phương pháp tiếp xúc đơn sang phương pháp tiếp xúc kép, hấp thụ kép.

- Hệ thống thu bụi xử lý khí thải, nước thải của công ty Phân lân nung chảy Vân Điền cũng giảm định mức tiêu hao than $24 \%$, điện $20 \%$, giải quyết triệt để bụi thải và các thành phần độc hại.

- Công ty Phân đạm và Hóa chất Hà Bắc cũng đã nghiên cứu thiết kế hệ thống công nghệ xử lý xy-a-nua, $\mathrm{H} 2 \mathrm{~S}$ (sun-phua hy-đrô) trong nước thải tuần hoàn rửa khí ở xưởng khí hóa than, hoàn thiện công nghệ chưng thu hồi a-mô-ni-ắc trong nước thải sản xuất.

Mặc dù chính phủ các nước cũng như các tổ chức môi trường đã có rất nhiều chính sách, giải pháp được đề ra nhưng vẫn còn tồn tại những thiếu sót trong việc khắc phục ô nhiễm hóa chất. Các hiệp ước quốc tế và các văn kiện tự nguyện đã giảm thiểu rủi ro của một số hóa chất và chất thải, nhưng tiến độ chưa đồng đều và vẫn còn thiếu sót trong quá trình thực hiện. Tính đến năm 2018, hơn 120 quốc gia đã không triển khai Hệ thống hài hòa toàn cầu về phân loại và ghi nhãn hóa chất. Liên quan đến công ước Stockholm về các chất ô nhiễm hữu cơ có phân hủy, đã có một số chỉ trích đối với công ước này đó là buộc công ước phải chịu nhiệm cho việc làm tiếp diễn các ca tử vong do sốt rét gây ra vì dùng chất DDT để kiểm soát muỗi. 
Ô nhiễm do hóa chất là vấn đề toàn cầu. Các hóa chất độc hại được tìm thấy trong tất cả các hệ sinh thái trên Trái đất, do đó ảnh hưởng tới đa dạng sinh học, sản xuất nông nghiệp và môi trường nước. Hóa chất sẽ được tái tạo hoặc thải ra như là một phần của chất thải vào cuối vòng đời sử dụng. Sự quản lý không đúng các chất thải đó gây ảnh hưởng xấu tới sức khỏe con người và môi trường. Như vậy, trước tình trạng ô nhiễm hóa chất hiện nay, chính phủ các nước cùng với các tổ chức trên thế giới cần tiếp tục ban hành những chính sách, giải pháp phù hợp, hiệu quả để ứng phó với tình trạng này.

\section{TÀI LIỆU THAM KHẢO}

[1] Sở Y tế TP. Hồ Chí Minh, "Hoá chất và tác động lên sức khoẻ con người: những điều đã biết và chưa biết," 2018.

https://medinet.gov.vn/quan-ly-chat-luong-kham-chua-benh/hoa-chat-va-tac-d ong-len-suc-khoe-con-nguoi-nhung-dieu-da-biet-va-chua-biet-so-cmobile8-93 73.aspx?fbclid=IwAR2N1IOVTWh6TiHmPuaZaZIEIaiFvdzcMOYKgRjjn-TA9Oq1TUb1r6tZ2E (accessed Dec. 16, 2021).

[2] “Mười thành phố ô nhiễm nhất thế giới,” 2007. https://nhandan.vn/tin-tuc-the-gioi/muoi-thanh-pho-o-nhiem-nhat-the-gioi-43 9940 (accessed Dec. 16, 2021).

[3] IPEN (International Pollutants Elimination Network), "China Chemical Safety Project (2012 - 2014)." https://ipen.org/projects/china-chemical-safety-project-2012--2014?fbclid=IwAR2IXGy90Qtx268h-n6WQbL7BS8TceXRgAf16tBgJJP5H LUeCNCgS-DWU-Y (accessed Dec. 16, 2021).

[4] United Nations Environment Programme, Triển vọng hóa chất toàn cầu. 2019.

[5] “Kiểm soát và giảm ô nhiễm trong ngành hóa chất," 2014. https://nhandan.vn/tin-tuc-kinh-te/kiem-soat-va-giam-o-nhiem-trong-nganh-h oa-chat-202891?fbclid=IwAR2f6XmqkLfR-CGcep4jTOBm2PWcLDZMrwU XqHia9je0o5E2RL-DcbZakZs (accessed Dec. 16, 2021). 
